LOVE'S SHADOW 



\title{
LOVE'S SHADOW
}

\author{
PAUL A. BOVÉ
}

\section{II \\ II \\ Harvard University Press}

Cambridge, Massachusetts

London, England

2021 
Copyright () 2021 by the President and Fellows of Harvard College All rights reserved Printed in the United States of America

\section{First printing}

Cover art: (top) turtix/iStock/Getty Images Plus; (bottom) Rembrandt van Rijn (1609-1669), Young woman sleeping on her right arm (Hendrickje Stoffels), c. 1654. Brush drawing in brown wash, with some white bodycolor. () The Trustees of the British Museum

$$
\begin{gathered}
\text { Cover design: Jill Breitbarth } \\
9780674249875 \text { (EPUB) } \\
9780674247628 \text { (MOBI) } \\
9780674247635 \text { (PDF) }
\end{gathered}
$$

The Library of Congress has cataloged the printed edition as follows:

Names: Bové, Paul A., 1949- author.

Title: Love's shadow / Paul A. Bové.

Description: Cambridge, Massachusetts : Harvard University Press, 2021. I Includes bibliographical references and index.

Identifiers: LCCN 2020011256 | ISBN 9780674977150 (cloth)

Subjects: LCSH: Criticism. I Intellectual life. I Poetry. I Melancholy. Classification: LCC PN81 .B62 2021 I DDC 808.1—dc23

LC record available at https://lccn.loc.gov/2020011256 
For the reader within 
